\title{
Profiling the Arctic Stable Boundary Layer in Advent Valley, Svalbard: Measurements and Simulations
}

\author{
Stephanie Mayer • Marius O. Jonassen • \\ Anne Sandvik · Joachim Reuder
}

Received: 1 February 2011 / Accepted: 14 February 2012 / Published online: 20 March 2012

(C) The Author(s) 2012. This article is published with open access at Springerlink.com

\begin{abstract}
The unmanned aerial system SUMO (Small Unmanned Meteorological Observer) has been used for the observation of the structure and behaviour of the atmospheric boundary layer above the Advent Valley, Svalbard during a two-week period in early spring 2009. Temperature, humidity and wind profiles measured by the SUMO system have been compared with measurements of a small tethered balloon system that was operated simultaneously. It is shown that both systems complement each other. Above $200 \mathrm{~m}$, the SUMO system outperforms the tethered balloon in terms of flexibility and the ability to penetrate strong inversion layers of the Arctic boundary layer. Below that level, the tethered balloon system provides atmospheric profiles with higher accuracy, mainly due to its ability to operate at very low vertical velocities. For the observational period, a numerical mesoscale model has been run at high resolution and evaluated with SUMO profiles reaching up to a height of $1500 \mathrm{~m}$ above the ground. The sensitivity to the choice of atmospheric boundary-layer schemes and horizontal resolution has been investigated. A new scheme especially suited for stable conditions slightly improves the temperature forecast in stable conditions, although all schemes show a warm bias close to the surface and a cold bias above the atmospheric boundary layer. During one cold and cloudless night, the SUMO system could be operated nearly continuously (every 30-45 minutes). This allowed for a detailed case study addressing the structure and behaviour of the air column within and above Advent Valley and its interaction with the local topography. The SUMO measurements in conjunction with a 10 -m meteorological mast enabled the identification of a very stable nocturnal surface layer adjacent to the valley bottom, a stable air column in the valley and a strong inversion layer
\end{abstract}

S. Mayer $\cdot$ M. O. Jonassen $\cdot$ J. Reuder

Geophysical Institute, University of Bergen, Allegaten 70, 5007 Bergen, Norway

S. Mayer $(\varangle)$

Uni Bjerknes Centre, Uni Research, Bjerknes Centre for Climate Research, Allegaten 70, 5007 Bergen,

Norway

e-mail: stephanie.mayer@uni.no

A. Sandvik

Institute of Marine Research, Nordnesgate 50, P.O. Box 1870 Nordnes, 5817 Bergen, Norway 
above the summit height. The results indicate the presence of inertial-gravity waves during the night, a feature not captured by the model.

Keywords Atmospheric profiles - Boundary-layer schemes · High-resolution numerical model · Inertial-gravity oscillation · Small Unmanned Meteorological Observer (SUMO) measurements $\cdot$ Stable Arctic atmospheric boundary layer

\section{Introduction}

In numerical weather prediction (NWP) there is a continuous demand for meteorological observations for initialization purposes and data assimilation, as well as for model evaluation and validation. Commonly, surface observations, satellite data and radiosonde data are applied for this purpose. To assess local scale atmospheric boundary-layer (ABL) phenomena, special in-situ measurement tools are required, such as masts, radiosondes, tethered balloons, kites or aircraft, and remote measurement techniques (e.g. sodar or lidar). These methods have all their advantages and shortcomings (e.g. Seibert et al. 2002).

During the last decade, the utilization of remotely piloted vehicles, also termed unmanned aerial systems (UAS), has become increasingly popular in the atmospheric sciences as a cost-efficient and flexible measurement alternative. So far, UAS of different size and complexity have been developed and applied to atmospheric measurements. Several of these UAS, such as the Aerosonde (Curry et al. 2004), the Meteorological Mini Unmanned Aerial Vehicle ( $\mathrm{M}^{2} \mathrm{AV}$ ) (van den Kroonenberg et al. 2008) and the Small Unmanned Meteorological Observer (SUMO) introduced by Reuder et al. (2009), have already been successfully used for missions in polar regions. UAS have a huge potential to improve our limited observational capabilities in Arctic regions where the observational network is sparse. Compared to other profiling platforms, such as kites, tethered balloons or radiosondes, small UAS require significantly less infrastructure. Provided that the system is equipped with a temperature, humidity and pressure sensor, numerous ABL phenomena can be observed by flying consecutive vertical profiles, including the diurnal variation in stratification, in particular inversion layers and subsidence. Adding a wind measurement system enables the investigation of dynamic processes such as low-level jets and orographically induced gravity waves. Mayer et al. (2010) used SUMO data obtained during the FLOHOF field campaign in central Iceland in summer 2007 (Reuder et al. 2011) to show the potential of UAS data for the evaluation of ABL parametrization schemes in the Weather Research and Forecasting model (WRF).

Numerical weather prediction and climate models often fail to appropriately reproduce the stable ABL in polar regions (Mahrt 1998; Dethloff et al. 2001; Tjernström et al. 2005), and this shortage in forecast skill for Arctic regions is well documented by Tjernström et al. (2004) and Galperin et al. (2007). The latter defined the so-called 'nordic temperature problem' where NWP forecasts notoriously result in a warm bias in predicting near-surface temperatures in conditions where the temperature falls below $-25^{\circ} \mathrm{C}$. The observed deviations between model and measurements in the intensity and development of the stable ABL are caused by a combination of insufficient coverage in the observational network to minimize the model initialization errors, and the limited understanding and representation of the relevant atmospheric key processes in particular in the presence of strong or extreme surface inversions, and the corresponding reduced vertical exchange of heat. During the Arctic winter and early spring, the absence or low values of solar radiation and the high albedo of snow and ice minimize the influence of solar heating from the ground, creating extended periods of high static stability and strong surface inversions. Such very stable boundary layers are 


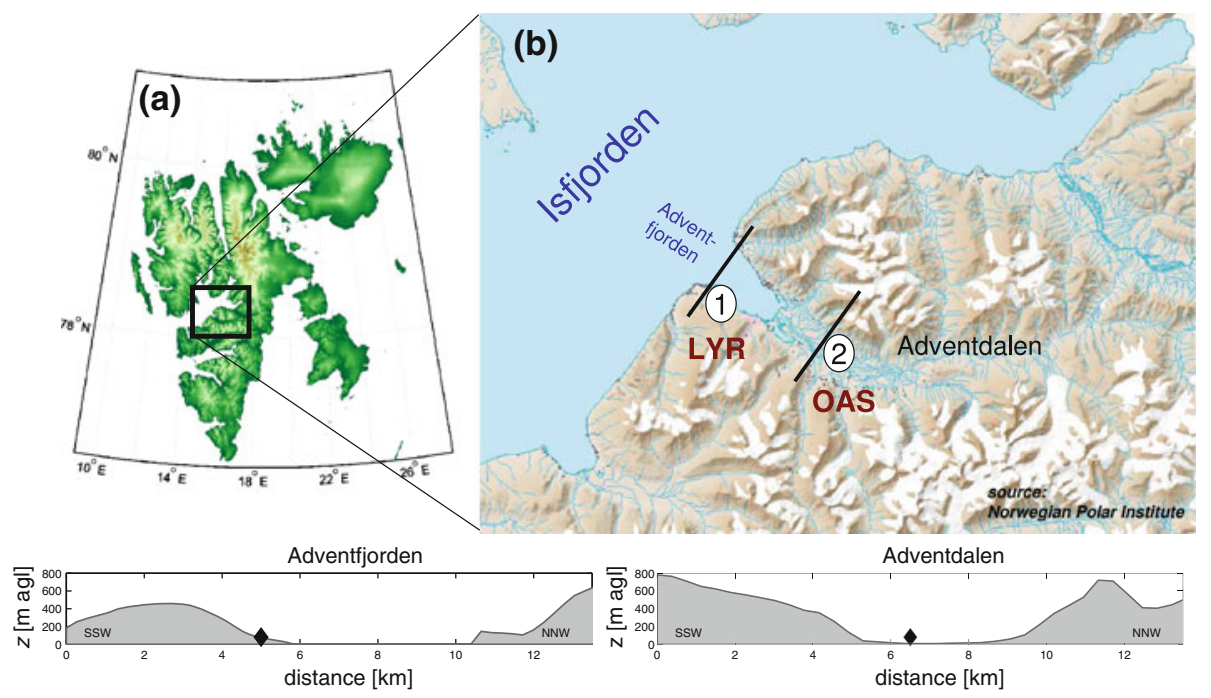

Fig. 1 a Topographic map of Svalbard. b Region of Isfjorden; numbers indicate the measurement sites; 1 Longyear airport (LYR) at the coastline of Isfjorden, the corresponding cross-section is shown in the lower left panel. 2 the old Auroral Station (OAS) in Advent Valley, the corresponding cross-section is shown in the lower right panel

in general poorly understood (Mahrt 1998). Under such conditions additional pathways of energy transfer are not sufficiently reproduced by numerical models, e.g. by the interaction between atmospheric turbulence and gravity waves, and are expected to be relatively more important (Zilitinkevich and Baklanov 2002) compared to other processes such as advection, radiative cooling or heat exchange between the atmosphere and the open or ice-covered ocean. In particular, in complex terrain close to the coast, as in the Svalbard fjords, where mountains of $1000 \mathrm{~m}$ height or so trigger gravity waves in the stable atmosphere, those effects should be considerable. Further improvement to our understanding of these processes, and the ability to improve the corresponding model parametrization schemes in the future, is strongly dependent on the availability of in-situ atmospheric measurements. In general, atmospheric observations are rare in the Arctic due to harsh weather conditions and the lack of sufficient infrastructure. However, the settlement of Longyearbyen provides a unique infrastructural and scientific environment due to its airport and the University centre in Svalbard (UNIS). Longyearbyen is located at the mouth of Advent Valley leading to Isfjorden (see Fig. 1). Svalbard's topography is characterized by mountain ranges (reaching a maximum altitude of around $1700 \mathrm{~m}$ above sea level) and deep fjords. Due to the proximity of the Arctic Ocean and the Fram Strait, the climate and weather conditions of Svalbard are additionally influenced by varying sea-ice conditions around the archipelago and inside the fjords. Overall, this results in rapid changes of different land-surface types (e.g. snow-covered land, sea ice, open water) over small horizontal distances.

Typically, the Isfjorden region is influenced by two main flow conditions: either by southwesterly winds that advect relatively warm and humid air from Fram Strait, or by northeasterly winds that transport cold and dry air from the Arctic Ocean over the archipelago (Hanssen-Bauer and Førland 2001) resulting in high dynamical variability (such as gravity waves) induced by the complex mountainous topography (Skeie and Grønås 2000). In low 
wind and clear-sky situations during nighttime, cold pools associated with extreme surface inversions can develop in the mountain valleys.

Our main objectives in this study are to investigate, (i) the operational reliability of SUMO in very cold atmospheric conditions, (ii) a direct comparison of SUMO with a tethered balloon, (iii) the evaluation of three ABL parametrizations embedded in the Weather Research and Forecasting model WRF, and (iv) the observation of orographically modified flows.

The remainder of the paper has the following structure: Sect. 2 describes the field campaign and observational set-up. The SUMO system is described in Sect. 3; regulatory issues as well as data quality compared to a tethered balloon system are discussed, thus accounting for the first two objectives. In Sect. 4, the numerical model set-up and chosen physical options for the model integrations are explained. Objectives (iii) and (iv) are addressed in Sects. 5 and 6, while a summary is presented in Sect. 7.

\section{The Field Campaign}

The archipelago of Svalbard is a special location due to its high latitude and proximity to the Arctic Ocean, stretching from $76^{\circ}-81^{\circ} \mathrm{N}$ and from $10-28^{\circ} \mathrm{E}$ (see Fig. 1a). The field campaign was conducted in the period 21 March until 5 April 2009, which is the late winter season at Svalbard. After the 3-month long polar night, direct solar insolation becomes positive at Longyearbyen and Advent Valley in March. The valley is nearly east-west orientated and has its exit at Longyear airport then leading to Isfjorden (Fig. 1b), the largest fjord at the western coast of Svalbard. Two main measurement sites have been chosen for investigating the stable Arctic ABL: site 1 was located at Longyear airport in close vicinity to the sea, enabling easy profiling access for the SUMO system over open or sea-ice covered ocean. Site 2 was located at the old Auroral Station about $15 \mathrm{~km}$ to the east of Longyear airport. Both sites provided the infrastructure for a relatively comfortable performance of the SUMO flight missions.

\subsection{Measurement Site 1: Longyear Airport $\left(78^{\circ} 14^{\prime} 46^{\prime \prime} \mathrm{N}, 15^{\circ} 27^{\prime} 56^{\prime \prime} \mathrm{E}\right)$}

At Longyear airport, the Norwegian Meteorological Institute (met.no) conducts routine meteorological measurements of 2-m temperature $(T), 10-\mathrm{m}$ wind speed $(f)$ and wind direction $(d d)$, and pressure $(p)$. At this site, 41 SUMO flights have been performed up to a height of $1500 \mathrm{~m}$ above ground level (a.g.l.) which was the maximum altitude approved by the Norwegian Civil Aviation Authority (Luftfartstilsynet). From 23 March until 5 April 2009 UNIS operated a tethered balloon system at the northern end of the runway. With the tethered balloon system, 27 temperature, humidity, wind speed and wind direction profiles were measured during this period (Manninen 2009). The lower left panel in Fig. 1 shows a cross-section of the valley topography at Longyear airport (black diamond).

\subsection{Measurement Site 2: Old Auroral Station $\left(78^{\circ} 12^{\prime} 08^{\prime \prime} \mathrm{N}, 15^{\circ} 49^{\prime} 42^{\prime \prime} \mathrm{E}\right)$}

The old Auroral station is located about $15 \mathrm{~km}$ east of Longyear airport, and is an abandoned research station that was used during the field campaign. It is located close to sea level roughly in the middle of the $4 \mathrm{~km}$ wide Advent Valley, to the north and south surrounded by mountain ranges reaching about $800 \mathrm{~m}$ at a distance of $5 \mathrm{~km}$ (see Fig. 1 lower right panel). The valley's main orientation is east-west (approximately $120^{\circ}$ ) while several smaller side-valleys open into the main valley close to the station area, making the Auroral Station a rather orographically complex site that seems to be well suited for investigations of orographic modification 

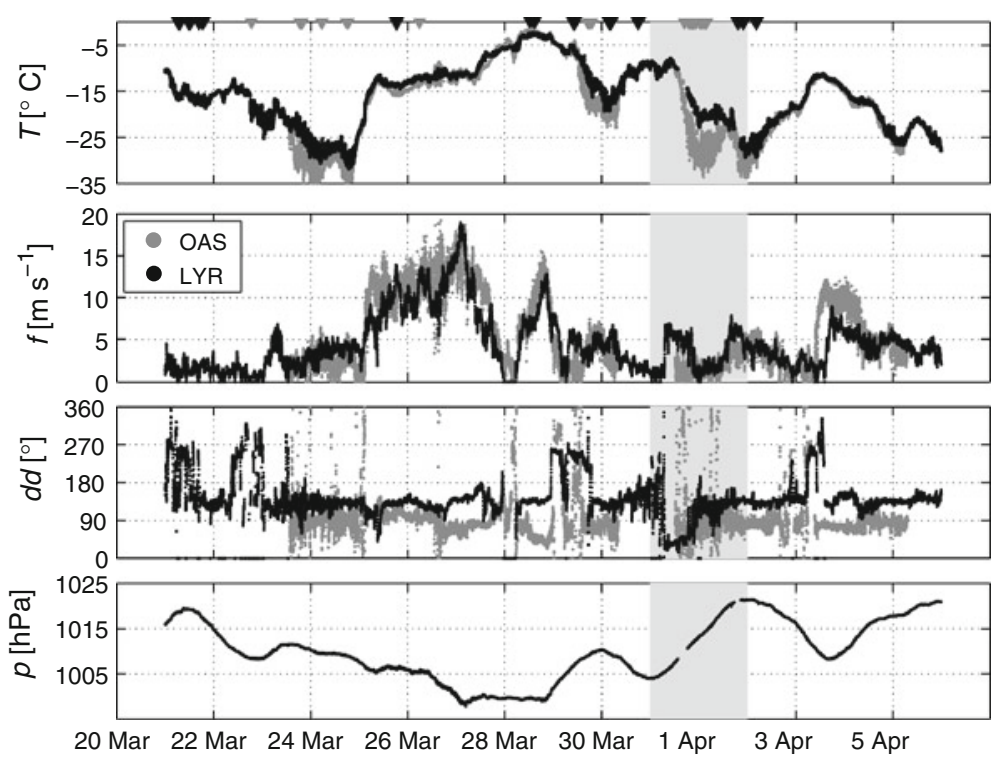

Fig. 2 Automatic weather station measurements (temporal resolution: $1 \mathrm{~min}$ ) during the field campaign at the old Auroral station (grey line) and at Longyear airport (black line). SUMO flights at the two locations listed in Table 2 are indicated as triangles in the corresponding colour in the top panel

of flows, e.g. the influence of gravity waves on atmospheric profiles or katabatic and drainage inflow close to the ground. For the field experiment, a 10-m mast equipped with temperature, humidity sensors and anemometers (2, 6 and 10-m ) was set-up. The lower right panel of Fig. 1 displays the topography at the Auroral Station (black diamond), and at this site 46 SUMO flights have been performed.

\subsection{Synoptic Situation During the Field Campaign}

During the field campaign, fair weather conditions with clear sky, light winds and low air temperature have been interrupted by the passage of a low pressure system accompanied by warm-air advection and strong winds from 25 until 29 March 2009 (see Fig. 2). At night with clear sky and light winds, the surface observations from the Auroral Station show substantially lower temperatures compared to Longyear airport. This might be due to drainage flows from snow covered side-valleys and mountain slopes contributing to continuous cooling and the development of a cold pool in the valley. From 31 March until 2 April, Svalbard was influenced by a cold-air outbreak situation.

\section{Measurements with the Small Unmanned Meteorological Observer SUMO}

\subsection{The SUMO System}

The SUMO system used in this study was developed at the Geophysical Institute at the University of Bergen in cooperation with Müller Engineering (www.pfump.org) and the Paparazzi Project (http://paparazzi.enac.fr) (Jonassen 2008; Reuder et al. 2009). 
Fig. 3 The SUMO airframe (based on FunJet construction kit by Multiplex). The airframe has a wingspan of $0.8 \mathrm{~m}$, and take-off weight of $0.58 \mathrm{~kg}$

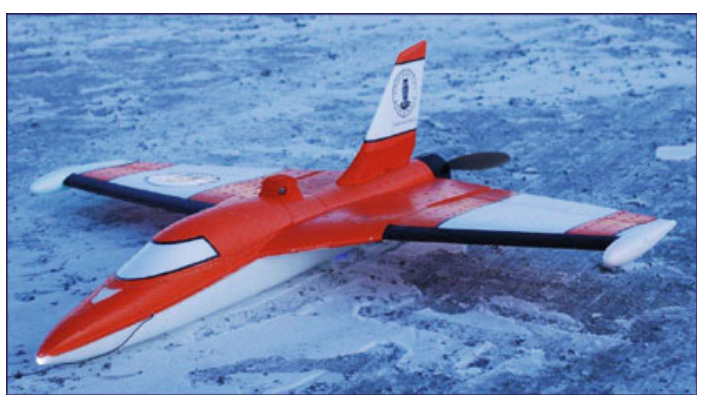

It consists of an airframe based on the FunJet construction kit by Multiplex (see Fig. 3), has a length and wingspan of around $0.8 \mathrm{~m}$ and a take-off weight of $0.58 \mathrm{~kg}$. SUMO is electrically powered by rechargeable Lithium-Polymer batteries with a pusher propeller in the rear of the aircraft and has a typical flight endurance of 25 minutes. For autonomous operation, SUMO is equipped with the Paparazzi autopilot system (Brisset et al. 2006). Currently, SUMO carries a basic meteorological sensor package consisting of a combined temperature and humidity sensor mounted in a radiation shield tube on the wing of the aircraft and a pressure sensor located inside the fuselage. The determination of wind profiles by SUMO in its recent version is based on an indirect method without an on-board flow sensor. Operating SUMO in circular or helical flight patterns with constant throttle and constant pitch angle results in approximately constant true air speed. The ground speed, which is continuously recorded by the autopilot's GPS receiver, can be used to calculate profiles of wind speed and direction by applying the Nelder-Mead minimization algorithm (Mckinnon 1996; Mayer et al. 2012).

The operation of SUMO in its actual version is limited to wind speeds below $18 \mathrm{~m} \mathrm{~s}^{-1}$. As the in-flight stabilization of SUMO in autonomous flight mode is accomplished by a set of infra-red sensors using the difference in radiation temperature between the ground and sky to define a flight horizon, SUMO cannot fly autonomously in weather situations with a radiation temperature difference less than $8 \mathrm{~K}$ between ground and sky. This prevents operation in or under clouds. An improved version of the autopilot, using an inertial measurement unit for stabilization and attitude control was implemented in 2011 and now overcomes this limitation. The SUMO version used in the Svalbard field campaign did not have a turbulence probe, which is now installed in the newest version. So far, the system has proven its functionality in more than 650 scientific flight missions during the last five years.

Typically, SUMO is operated in a helical flight pattern with a climb speed of $6-10 \mathrm{~m} \mathrm{~s}^{-1}$ during ascent and 2-4 $\mathrm{m} \mathrm{s}^{-1}$ during descent. Raw data are sampled and stored with a frequency of $2 \mathrm{~Hz}$, which results in a vertical resolution of $<5 \mathrm{~m}$ during ascent and $<2 \mathrm{~m}$ during descent. In the post-processing routine, data are averaged over height intervals $\Delta z=20 \mathrm{~m}$, starting at $z=10 \mathrm{~m}$ a.g.l. resulting in a coarser vertical resolution compared to the tethered balloon. Due to the relatively fast climb speed of SUMO, the temperature and humidity measurements have to be corrected for a sensor time-lag error, and a numerical correction scheme based on digital filters is applied to correct for the slow sensor response. This correction is performed in the post-processing routine thoroughly described by Jonassen (2008). In this study, we present data obtained in descent mode when SUMO is operated with a slower climb speed that ensures an improved data quality. SUMO's wind information is only shown for heights between 200 and $1250 \mathrm{~m}$ a.g.l., and below $200 \mathrm{~m}$ a.g.1., SUMO is operated manually, thus the wind algorithm cannot be applied. At ceiling altitude SUMO switches from ascent to descent mode and the assumption of constant throttle and pitch angle is violated. Therefore, 
wind data for levels above $1250 \mathrm{~m}$ are not trustworthy. For more technical details of the SUMO system, see Reuder et al. (2009) and Jonassen (2008).

\subsection{Regulatory Issues}

For the SUMO missions during the field campaign, flight permission had to be approved by Luftfartstilsynet, the Norwegian Civil Aviation Authority (CAA) in Bodø. A general permission to operate SUMO up to heights of $1500 \mathrm{~m}$ a.g.l. was issued by CAA with the constraint that every flight had to be cleared by the tower at Longyear airport. This meant in practice that SUMO flights were only permitted when the airport was officially closed and no other irregular air traffic, as manned research flights and search and rescue operations were ongoing. As a result, most SUMO flights have been conducted at nighttime and during the weekends. From the authors' point of view this was a very strict and unnecessary limitation that unfortunately disabled the performance of subsequent profiles by SUMO during a whole diurnal cycle in order to monitor the development of the ABL. A typical profiling mission of SUMO takes around 25 minutes. In the event of an emergency, however, the aircraft's autopilot provides a descent function for a safe recovery from $1500 \mathrm{~m}$ a.g.l. within less than three minutes at any time of the mission. As the control tower is informed about any kind of air traffic approaching the airport well in advance (one hour or more, except for emergency rescue operations), distinctly more SUMO missions could have been performed without any violation of general aviation safety.

\subsection{Comparison with Tethered Balloon Measurements}

During the field campaign, a tethered balloon system was operated in the vicinity of the SUMO measurement site 1 at Longyear airport, at the western end of the airport's runway. These data are used for a comparison and data quality control of the SUMO measurements. Defining a maximum acceptable time slot of one hour between SUMO and tethered balloon ascents, 15 out of a total of 27 tethered balloon profiles could be used for inter-comparison purposes. One typical example is shown in Fig. 4; the tethered balloon data have a vertical resolution of $1 \mathrm{~m}$, while the SUMO data are averaged over $20 \mathrm{~m}$. Therefore the SUMO profiles (black line) have a smoother structure. In the lowest $100 \mathrm{~m}$, the tethered balloon observations connect the surface measurements almost perfectly to the SUMO profiles, and overall, both measurement systems agree reasonably well. The temperature profiles show good agreement with maximum deviations less than $1 \mathrm{~K}$. The gradients and fine-scale structures match well. A slight bias in altitude occurs that can be associated with the slow sensor response in combination with the higher descending velocity of the SUMO system for the presented profile. The relative humidity measurements (Fig. 4b) of both systems show the same structure and vertical gradient. The SUMO agrees well with the automatic weather station (AWS). However, the tethered balloon measured distinctly lower absolute values compared to SUMO and the AWS, and was most likely caused by a calibration offset in the tethered balloon system. The wind-speed profiles agree well (Fig. 4c), with both wind-speed profiles showing values between 2-4 $\mathrm{m} \mathrm{s}^{-1}$ with some differences in a vertical structure. SUMO shows a stronger vertical shear at $400 \mathrm{~m}$ a.g.l., and might be due to the horizontal distance between the measurement systems as well as unsteady wind conditions due to the complex topography. It can be clearly seen that the tethered balloon was unable to penetrate the second layer of a stronger wind shear at $600 \mathrm{~m}$ a.g.l. where SUMO measured a wind speed of $6 \mathrm{~m} \mathrm{~s}^{-1}$. This height corresponds to the temperature inversion in Fig. 4a. The wind-direction profile agrees quite well in the shown profile (Fig. 4d). 

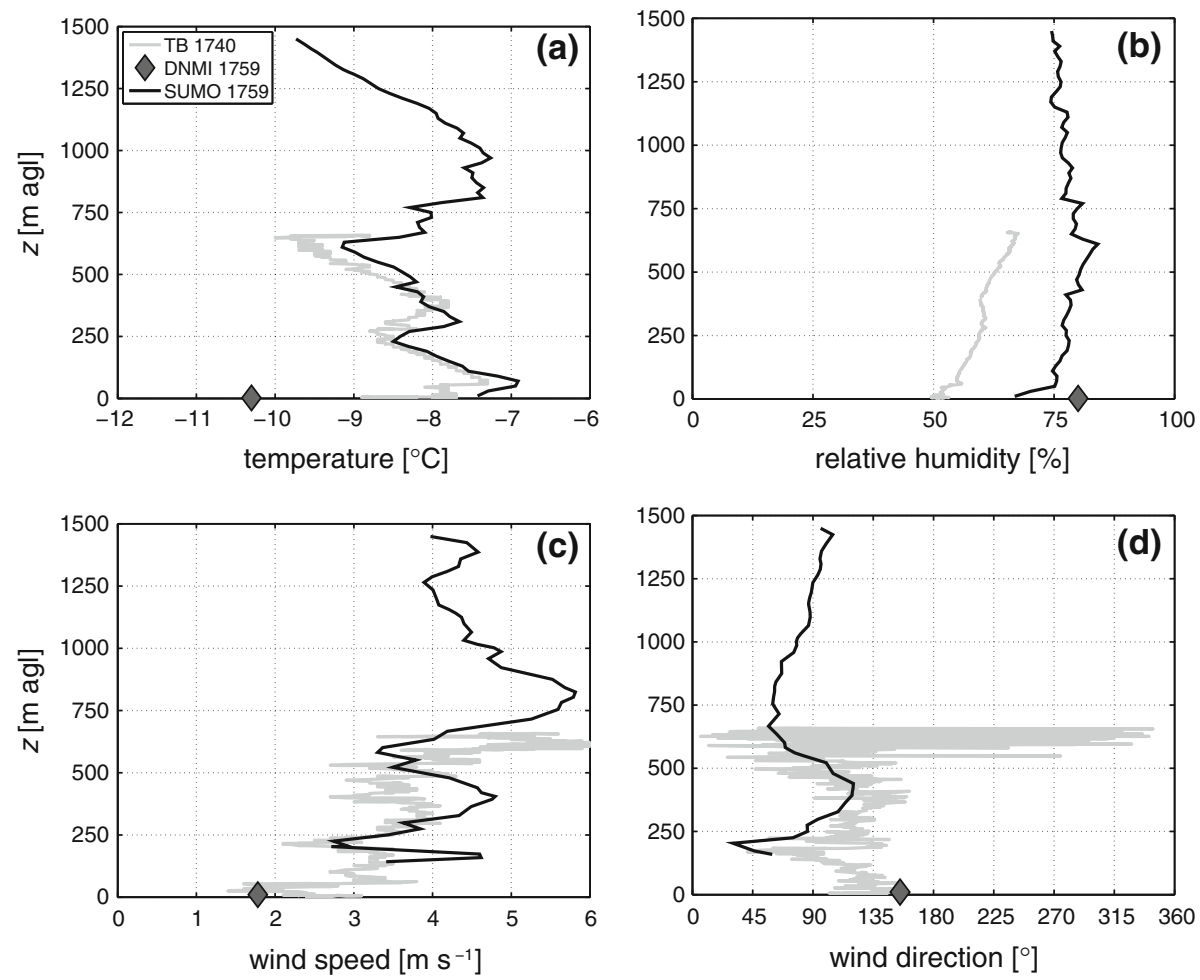

Fig. 4 Profiles measured on 30 March 2009 at 1800 UTC. a Temperature, b relative humidity c wind-speed and $\mathbf{d}$ wind-direction profiles measured with the tethered balloon (TB) system (grey line) and the SUMO system (black line). Diamonds indicate measurements from the automatic weather station

The major benefit of the tethered balloon system is the low vertical velocity that can be realized, which is particularly important for the resolution of e.g. strong surface inversion layers. Such inversions are at the moment not appropriately resolvable by SUMO. Thus, the SUMO system has further potential for improvement concerning data quality for temperature and humidity measurements below approximately $50 \mathrm{~m}$. Due to the 'no-flow-sensor' wind estimation algorithm that only works in autonomous flight mode, wind speed could only be estimated for $z>200 \mathrm{~m}$ a.g.l. In general, tethered balloon and SUMO should not be seen as competitors for the purpose of ABL measurements, but as two systems that highly complement each other, mainly using data from the tethered balloon system to fill the gap of information from reliable SUMO measurements down to the operational surface measurements at $2 \mathrm{~m}$, respectively $10 \mathrm{~m}$ for wind. The experience with SUMO and tethered balloon during the campaign also clearly showed that SUMO outperforms the tethered balloon system when it comes to the flexibility of measurements, the required infrastructure and in situations with elevated inversion layers that could not be penetrated by the tethered balloon. One prominent example can be seen in Fig. 4, where SUMO easily reached $1500 \mathrm{~m}$, while the relatively small tethered balloon with a volume of $2.5 \mathrm{~m}^{3}$ was not able to ascend higher than approximately $600 \mathrm{~m}$ due to a marked temperature inversion and wind-shear layer. 


\section{Model Configurations}

We used the Advanced Weather Research and Forecasting model WRF version 3.1.1 developed by the National Center of Atmospheric Research (NCAR). The WRF model integrates fully compressible non-hydrostatic equations with terrain-following hydrostatic-pressure vertical coordinates, and provides multi-nested domains and a large number of physical parameterizations. For a further detailed description of the model, see Skamarock et al. (2008).

The sensitivity to horizontal resolution due to the close coherency of wind and complex topography is a well-known feature (e.g. Sandvik and Furevik 2002; Schicker and Seibert 2009). Due to Svalbard's complex topography, a high horizontal resolution set-up of $9 \mathrm{~km}-$ $3 \mathrm{~km}-1 \mathrm{~km}$ centered at $78.5^{\circ} \mathrm{N}, 17.0^{\circ} \mathrm{E}$ has been chosen. The inner domains are two-way nested to their mother domain. The outer domain covers $120 \times 120$ grid points stretching from the north-east corner of Greenland in the west to Franz-Josef-Land in the east, while the second domain covers most parts of the Spitsbergen archipelago with $130 \times 155$ grid points. The innermost domain covers $160 \mathrm{~km}$ in the east-west and $175 \mathrm{~km}$ in the north-south direction including the region of Isfjorden, Longyearbyen and Advent Valley. All three domains have a high vertical resolution with 61 vertical terrain-following sigma levels, with the top at 50 $\mathrm{hPa}$ (approximately $15.5 \mathrm{~km}$ ). The lowest $1500 \mathrm{~m}$ include 29 model levels, with the lowest full level at $36 \mathrm{~m}$. A sensitivity test on the vertical resolution showed that 61 vertical levels are necessary to resolve ABL phenomena, such as the low-level jet. Note that doubling the model resolution increases the computational time by about $2^{4}=16$ times (roughly a factor of two for the three spatial dimensions and another factor of two for the smaller timestep).

Static fields such as land use and topographical data have been provided by the U.S. Geological Survey at a horizontal resolution of $30^{\prime \prime}(0.9 \mathrm{~km}$ in north-south direction). These latitude-longitude datasets are interpolated into the stereographic domains within the WRF pre-processing system.

For initial and lateral boundary conditions, data from the European Centre for MediumRange Weather Forecasts (ECMWF) are used, on a $0.5^{\circ} \times 0.5^{\circ}$ grid at 26 pressure levels that are updated every six hours. Thus, the WRF integrations can be considered as dynamical downscaling. For all three domains the Noah land-surface model (Chen and Dudhia 2001) has been used, and for the model integrations a timestep of $36 \mathrm{~s}$ has been chosen. The model has been run for the observational period starting on 20 March 20090000 UTC until 5 April 20090000 UTC allowing for a spin-up time of 24 hours as recommended in Hines et al. (2011) for polar environments.

Since the availability of the WRF model version 3.1, fractional sea-ice can be used in the integrations. As mentioned in Kilpeläinen et al. (2010), sea-ice in the ECMWF data is afflicted with errors in fjords and near coastlines. Therefore, the ECMWF sea-ice fields have been replaced by daily sea-ice concentration data provided by the Advanced Microwave Scanning Radiometer (data available at the National Snow and Ice Data Center http://nsidc. org/data/amsre/). However, after the pre-processing procedure in the WRF model there was still excessive sea-ice in Isfjorden. Therefore, sea-ice has been removed manually to be consistent with the daily met.no sea-ice charts (personal communication with T. Kilpeläinen, 2011).

\subsection{Model Physics}

As microphysical option, the single-moment 5-class scheme has been chosen that provides mixed-phase processes and super-cooled water. For the longwave radiation the Rapid Radiative Transfer Model scheme was used (Mlawer et al. 1997), and for the shortwave 
Table 1 Overview of the performed WRF runs

\begin{tabular}{llll}
\hline Run & ABL scheme & Two-way nested & Horizontal grid size (km) \\
\hline YSU-fb1-d03 & YSU & Yes & 1 \\
MYJ-fb1-d03 & MYJ & Yes & 1 \\
QNSE-fb1-d03 & QNSE & Yes & 1 \\
QNSE-fb0-d01 & QNSE & No & 9 \\
QNSE-fb0-d02 & QNSE & No & 3 \\
QNSE-fb0-d03 & QNSE & No & 1 \\
\hline
\end{tabular}

$f b 1$ two-way nesting has been activated, $f b 0$ two-way nesting has been deactivated, YSU Yonsei University scheme, MYJ Mellor-Yamada-Janjic scheme, QNSE Quasi Normal Scale Elimination scheme

radiation scheme, the Goddard scheme was activated; which is a two-stream multi-band scheme including cloud effects (Chou and Suarez 1999) radiative as well as snow-cover and cloud effects were activated. Leaving all physical options constant apart from the choice of ABL scheme, three different ABL configurations have been used. In WRF version 3.1 there are nine different ABL schemes available. As a default ABL scheme the Yonsei University (YSU) scheme (Hong et al. 2006; Hong and Kim 2007) is implemented in the model. This scheme is based on the original work of Troen and Mahrt (1986) that considers counter-gradient fluxes, diagnoses the ABL height and finally prescribes the $K$-profile over the ABL depth. Following Stull (1988) this scheme is first order and non-local.

An alternative is the Mellor-Yamada-Janjic (MYJ) ABL scheme (Janjic 1990, 1996, 2002), which can be classified as a 1.5-order local scheme where the turbulent kinetic energy (TKE) is computed through a prognostic equation and the diffusion coefficient as a function of the Richardson number and TKE.

A new option in WRF version 3.1 is the quasi-normal scale elimination (QNSE) scheme especially suited for the stable ABL. This scheme is based on the work of Sukoriansky and Galperin (2008) using local TKE-based vertical mixing. It successively eliminates small scales of motion and calculates following corrections to viscosity and diffusivity. It expresses analytically eddy viscosity, eddy diffusivity, kinetic energy and temperature spectra. Scale elimination to some extent provides a subgrid-scale representation of large eddies. The method traces the modification of the flow with increasing stratification and recovers growing anisotropy and the effect of internal waves (Sukoriansky and Galperin 2008).

Additionally to the three two-way nested runs, one model integration has been performed by using the QNSE scheme in a one-way nested configuration to test the sensitivity of the horizontal resolution. The performed WRF integrations are listed in Table 1.

\section{Evaluation of Atmospheric Boundary-Schemes in High-Resolution Model Runs}

For every model level $\sigma$ from the surface up to 1500 above the ground or correspondingly from $\sigma=1, \ldots, 28$, the mean error $(M E)$ and root-mean-squared error (RMSE) for the temperature forecast have been calculated for $N=52$ SUMO profiles reaching heights $z>900 \mathrm{ma.g} .1$. The corresponding flights are listed in Table 2. The same evaluation has been performed for the wind-speed forecast for the levels $\sigma=4, \ldots, 24$, and for the evaluation of the wind information, a reduced number of model levels was used due to the fact that the observed wind speed is not reliable close to the ground, and between the switch of 
the aircraft between ascent and descent as shortly reasoned in Sect. 3.1. We note that

$$
\begin{aligned}
M E & =\frac{1}{N} \sum_{i=1}^{N}\left(X_{\text {forecast }_{i}}-X_{\text {observed }_{i}}\right), \\
R M S E & =\sqrt{\frac{1}{N} \sum_{i=1}^{N}\left(X_{\text {forecast }_{i}}-X_{\text {observed }_{i}}\right)^{2} .}
\end{aligned}
$$

In Fig. 5 the result of the evaluation of WRF model integrations is shown, where in (a)(d) we see the profiles for Longyear airport and in (e)-(h) for the Auroral Station. For both locations the surface layer $(z<250 \mathrm{~m})$ in all model integrations (besides QNSE-9km-fb0) shows a warm bias of approximately $1-3 \mathrm{~K}$. At heights above $250 \mathrm{~m}$ the mean temperature bias ranges between -1 and $1 \mathrm{~K}$, which we consider as very good agreement of the WRF model with the SUMO measurements. However, at the Auroral Station, the model shows temperatures that are too low above $1200 \mathrm{~m}$. Little sensitivity in the choice of ABL scheme, but high sensitivity to horizontal resolution, is seen. The wind profiles for Longyear airport show an overall good agreement with the SUMO measurements, and the bias is approximately $1 \mathrm{~m} \mathrm{~s}^{-1}$ from 200 to $800 \mathrm{~m}$ a.g.l. The wind profile from the 9-km integration shows a substantially poorer result that can be related to the smoother topography in the model. For the Auroral Station, all model integrations show a too strong low-level jet at $250 \mathrm{~m}$ a.g.l., and at heights above $500 \mathrm{~m}$ a.g.l., all 1-km integrations perform well while the coarser resolution runs overestimate the wind speed in all layers. We see little sensitivity in the choice of the ABL parametrization scheme. However, the QNSE scheme performs slightly better in the lowest layers. The increase from 9-km to 1-km horizontal resolution in WRF model results in an improved wind forecast that is a well-known feature in the performance of NWP models in complex terrain. Since the three tested schemes show very similar results, we cannot conclude that the QNSE scheme substantially improves the near-surface temperature forecast for very stable conditions. Nevertheless, this has to be seen as a subtle hint since the evaluation period was quite limited. This result is not directly comparable with the study of Sukoriansky and Galperin (2008) where the QNSE scheme is used in the high resolution limited area model (HIRLAM) system and statistically evaluated against pressure, temperature, wind speed and relative humidity observations in France and Scandinavia for a longer period (January 2005). The latter showed that employing the QNSE scheme improved the skill of the 24-h and 48-h forecasts substantially.

\section{Case Study 31 March-1 April 2009}

During the campaign, minimum surface temperatures below $-30^{\circ} \mathrm{C}$ were observed during nights of fair weather i.e. during anticyclonic conditions with clear skies and low wind speeds (indicated by grey shading in Fig. 2). The development of such low temperatures and corresponding extreme surface inversions, was in addition favoured by the fact that Adventfjorden (see map in Fig. 1b) was mostly ice-covered during spring 2009. Similar situations have been described by Petersson (2007), for instance.

The lowest temperatures during the campaign $\left(T<-25^{\circ} \mathrm{C}\right)$ have been observed in two periods, from 23 until 25 March and from 31 March until 2 April. During both periods, the $10-\mathrm{m}$ wind speed was mostly below $5 \mathrm{~m} \mathrm{~s}^{-1}$ and the temperature difference between Longyear airport and the Auroral Station exceeded $5 \mathrm{~K}$ (not shown) due to the proximity of the Longyear airport to a patch of open sea along the coast adjacent the airport. For this case study we have focused on the most extreme cold episode, when the temperature difference 
Table 2 Overview of 52 SUMO soundings at Longyear airport (LYR) and at the old Auroral Station (OAS) reaching heights $z>900 \mathrm{ma.g} .1$.

\begin{tabular}{|c|c|c|c|c|}
\hline SUMO ID & Start date, time (UTC) & Max. height (m agl) & Duration (min) & Location \\
\hline 1 & 21 March 2009, 0636 & 1495 & 32 & LYR \\
\hline 2 & 21 March 2009, 0709 & 1488 & 28 & LYR \\
\hline 3 & 21 March 2009, 1137 & 1491 & 35 & LYR \\
\hline 4 & 21 March 2009, 1214 & 1495 & 28 & LYR \\
\hline 6 & 21 March 2009, 1643 & 1495 & 25 & LYR \\
\hline 8 & 21 March 2009, 1832 & 1499 & 27 & LYR \\
\hline 10 & 22 March 2009, 1837 & 1495 & 27 & OAS \\
\hline 15 & 23 March 2009, 1833 & 1495 & 32 & OAS \\
\hline 16 & 23 March 2009, 1909 & 1495 & 33 & OAS \\
\hline 17 & 23 March 2009, 1944 & 1407 & 34 & OAS \\
\hline 18 & 24 March 2009, 0514 & 1500 & 22 & OAS \\
\hline 19 & 24 March 2009, 0538 & 1495 & 23 & OAS \\
\hline 22 & 24 March 2009, 1737 & 1493 & 31 & OAS \\
\hline 23 & 24 March 2009, 1833 & 1495 & 30 & OAS \\
\hline 27 & 25 March 2009,1824 & 972 & 14 & LYR \\
\hline 30 & 26 March 2009, 0546 & 1495 & 21 & OAS \\
\hline 34 & $28 \operatorname{March} 2009,1251$ & 1413 & 18 & LYR \\
\hline 36 & 28 March 2009,1423 & 1088 & 27 & LYR \\
\hline 37 & $29 \operatorname{March} 2009,1005$ & 1495 & 25 & LYR \\
\hline 38 & 29 March 2009, 1030 & 1495 & 22 & LYR \\
\hline 39 & 29 March 2009, 1703 & 1495 & 26 & OAS \\
\hline 40 & $29 \operatorname{March} 2009,1739$ & 1499 & 12 & OAS \\
\hline 41 & $29 \operatorname{March} 2009,1813$ & 1495 & 25 & OAS \\
\hline 43 & $29 \operatorname{March} 2009,1906$ & 1495 & 27 & OAS \\
\hline 44 & 29 March 2009, 1906 & 1492 & 23 & OAS \\
\hline 46 & 30 March 2009, 0343 & 1495 & 21 & LYR \\
\hline 47 & 30 March 2009, 0430 & 1495 & 17 & LYR \\
\hline 48 & 30 March 2009, 0430 & 1495 & 29 & LYR \\
\hline 49 & 30 March 2009, 1759 & 1495 & 25 & LYR \\
\hline 50 & 30 March 2009, 1759 & 1496 & 23 & LYR \\
\hline 53 & 31 March 2009, 1652 & 1495 & 27 & OAS \\
\hline 55 & 31 March 2009, 1853 & 1495 & 28 & OAS \\
\hline 56 & 31 March 2009, 1932 & 1495 & 33 & OAS \\
\hline 57 & 31 March 2009, 1932 & 1495 & 32 & OAS \\
\hline 58 & 31 March 2009, 2005 & 1496 & 22 & OAS \\
\hline 59 & 31 March 2009, 2028 & 1494 & 20 & OAS \\
\hline 60 & 31 March 2009, 2048 & 1495 & 11 & OAS \\
\hline 61 & 31 March 2009, 2100 & 1495 & 23 & OAS \\
\hline 62 & 31 March 2009, 2124 & 1495 & 29 & OAS \\
\hline 63 & 31 March 2009, 2155 & 1495 & 47 & OAS \\
\hline 64 & 31 March 2009, 2242 & 1495 & 57 & OAS \\
\hline 66 & 1 April 2009, 0016 & 1495 & 41 & OAS \\
\hline 68 & 1 April 2009, 0057 & 1499 & 34 & OAS \\
\hline 70 & 1 April 2009, 0134 & 1495 & 40 & OAS \\
\hline 71 & 1 April 2009, 0215 & 1495 & 40 & OAS \\
\hline 72 & 1 April 2009, 0258 & 1495 & 36 & OAS \\
\hline 73 & 1 April 2009, 0334 & 1494 & 19 & OAS \\
\hline 74 & 1 April 2009, 0353 & 1495 & 38 & OAS \\
\hline 76 & 1 April 2009, 1927 & 1496 & 22 & LYR \\
\hline 77 & 1 April 2009, 2156 & 1495 & 26 & LYR \\
\hline 78 & 2 April 2009,0422 & 1497 & 23 & LYR \\
\hline 79 & 2 April 2009, 0422 & 1493 & 23 & LYR \\
\hline
\end{tabular}



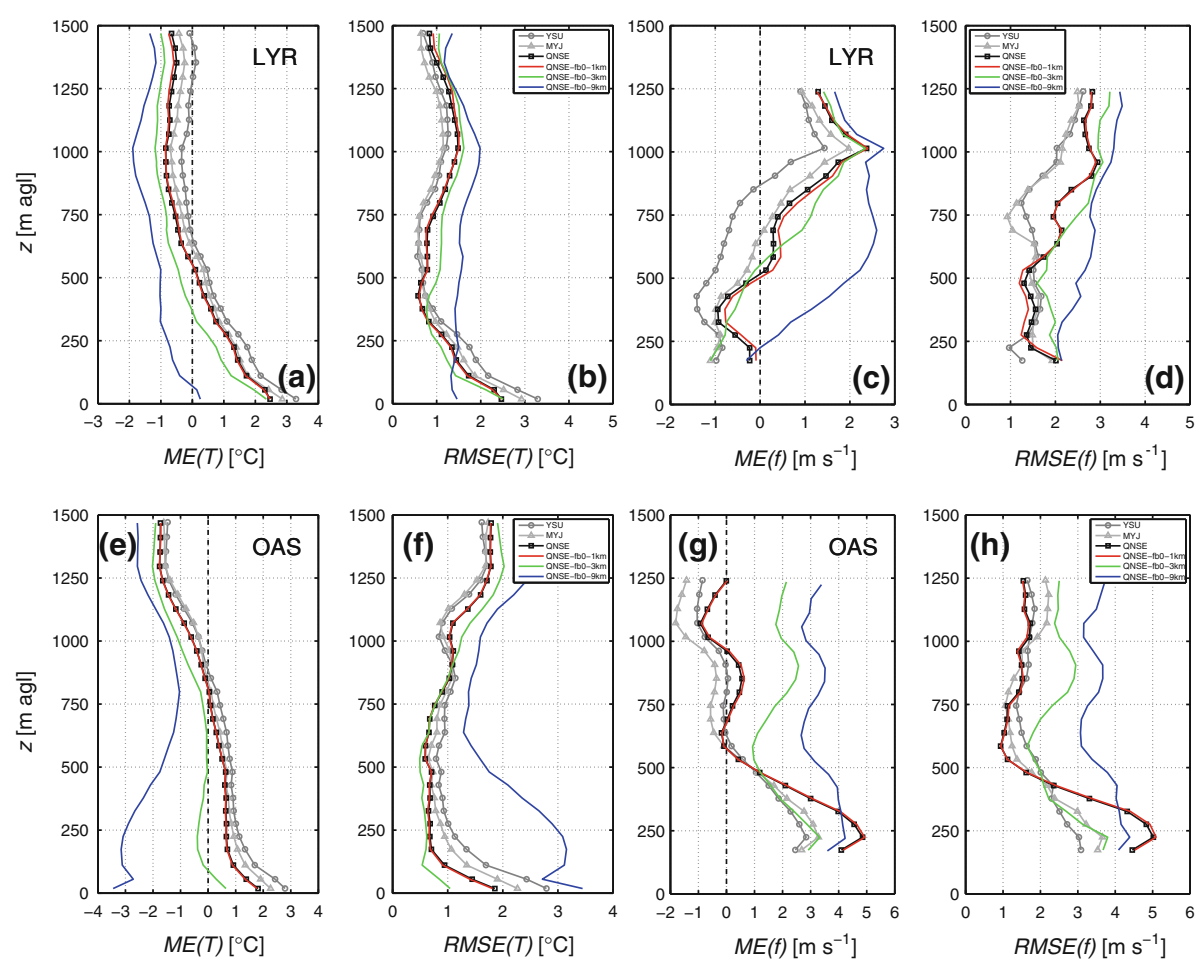

Fig. 5 Mean error (Eq. 1) and root-mean-square error (Eq. 2) of the ABL schemes (YSU, MYJ, QNSE) with respect to temperature and wind speed. a-d profiles at Longyear airport; $\mathbf{e}-\mathbf{h}$ profiles at the Auroral Station. Coloured profiles show the sensitivity to horizontal resolution $(9 \mathrm{~km}-3 \mathrm{~km}-1 \mathrm{~km})$ with de-activated feedback (fb0)

Fig. 6 MODIS terra satellite imagery (www.rapidfire.sci.gsfc. nasa.gov) for the region of Svalbard on 1 April 20091200 UTC showing the cold-air outbreak influencing the experiment region

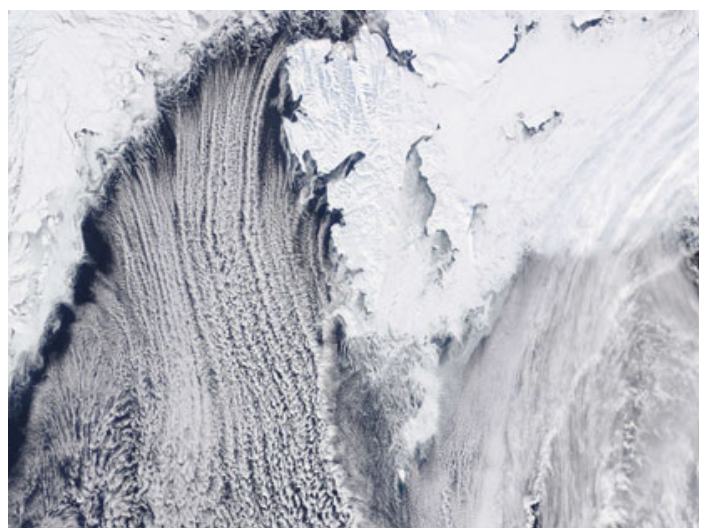

between the stations reached $14 \mathrm{~K}$. Here, also numerous SUMO profiles with a typical repetition frequency of about 30-45 minutes could be performed due to nearly perfect flight conditions, i.e. low wind, clear skies and most importantly no air-traffic restrictions during the night from 31 March until 1 April. 


\subsection{Synoptic Weather Conditions}

During the selected period, the archipelago of Svalbard was influenced by a cold-air outbreak that can be easily seen in the cloud streets appearing south of the sea-ice edge in the upper left corner of Fig. 6. The cold-air outbreak was triggered by a combination of an anticyclone over Greenland and a low-pressure system above the Barents Sea. The associated occlusion extended over Svalbard on 31 March 20090000 UTC (not shown); this synoptic constellation caused moderate northerly winds in the region.

\subsection{Profile Measurements}

Figure 7a, c, d shows the subsequently measured profiles of temperature $(T)$, potential temperature $(\Theta)$ and specific humidity $(q)$ during the selected case study obtained by SUMO from one hour before dusk (1700 UTC) until dawn (0400 UTC). Figure $7 \mathrm{~b}$ presents the results of a corresponding WRF model simulation of the studied period. In Fig. 7a the near-surface temperatures measured by the $10 \mathrm{~m}$ mast are added, and show a strong cooling at 2 -m height from $-16.5^{\circ} \mathrm{C}$ in the afternoon down to values below $-30^{\circ} \mathrm{C}$ during the night. The lowest layer above the snow-covered valley bottom (labelled by I in Fig. 7a) is very stably stratified with a temperature difference between $2 \mathrm{~m}$ and $10 \mathrm{~m}$ of $2-8 \mathrm{~K}$, also distinctly increasing in time.

Due to the lower vertical velocity of the SUMO system during descent $\left(2 \mathrm{~m} \mathrm{~s}^{-1}\right.$ in contrast to typically $6-10 \mathrm{~m} \mathrm{~s}^{-1}$ during ascent), minimizing the effects of the temperature sensor time constant, only the SUMO profiles taken during descent have been used for the following investigations. The SUMO data have been averaged over 20 -m intervals, with the lowest SUMO data point at $10 \mathrm{~m}$ above the ground (see also Sect. 3). The remaining temperature offset of 2-8 K between SUMO and mast temperatures at this level is a result of the delay due to the time constant of the SUMO temperature sensor in the strong inversion layer. The applied correction of the temperature sensor's time-lag error is not sufficient to resolve the actual strong temperature gradient in the surface-layer inversion.

The SUMO profiles identify stable stratification $(d \Theta / d z>0)$ in the whole probed column. The layers II $(50-750 \mathrm{~m})$ and IV $(1200-1500 \mathrm{~m})$ are moderately stable, while the marked inversion layer indicated by III (in $800-1200 \mathrm{~m}$ ) is very stable. It shows at the beginning an increase in $\Theta$ of around $5 \mathrm{~K}$ over $200 \mathrm{~m}$ at around $1000 \mathrm{~m}$. During the night, this inversion weakens $\left(d \Theta / d z=4 \mathrm{~K}(200 \mathrm{~m})^{-1}\right)$ and finally slightly descends to around $800 \mathrm{~m}$ in the morning. The level of the main inversion layer corresponds closely to the altitude of the surrounding mountains in the valley, creating a high potential for wave activity.

The time evolution in the measured temperature profiles reveals an overall cooling of 4-5 K during the course of 11 hours, in particular in the layers II and IV (see Fig. 7a)). The strong cooling in layer IV can mainly be addressed to advection related to the cold-air outbreak that is also reported from tethered balloon profiles in Ny-Ålesund and from the radiosonde on Bjørnøya (not shown). The strong cooling in the valley $(0-700 \mathrm{~m})$ is primarily due to enhanced outgoing longwave radiation during nighttime. Related katabatic and drainage effects in Advent Valley and from side valleys, such as Todalen may have intensified the strong nighttime cooling in the valley. Calculating the accumulated cooling after the method described by De Wekker and Whiteman (2006) using the first (1652 UTC) and last (0353 UTC) of the SUMO profiles results in $3.4 \mathrm{MJ} \mathrm{m}^{-2}$. The resulting nighttime cooling for snow-covered valleys of comparable size and surrounding topography coincides well with the observed temperature decrease of 4-5 K between sunset and sunrise (De Wekker and Whiteman 2006). 

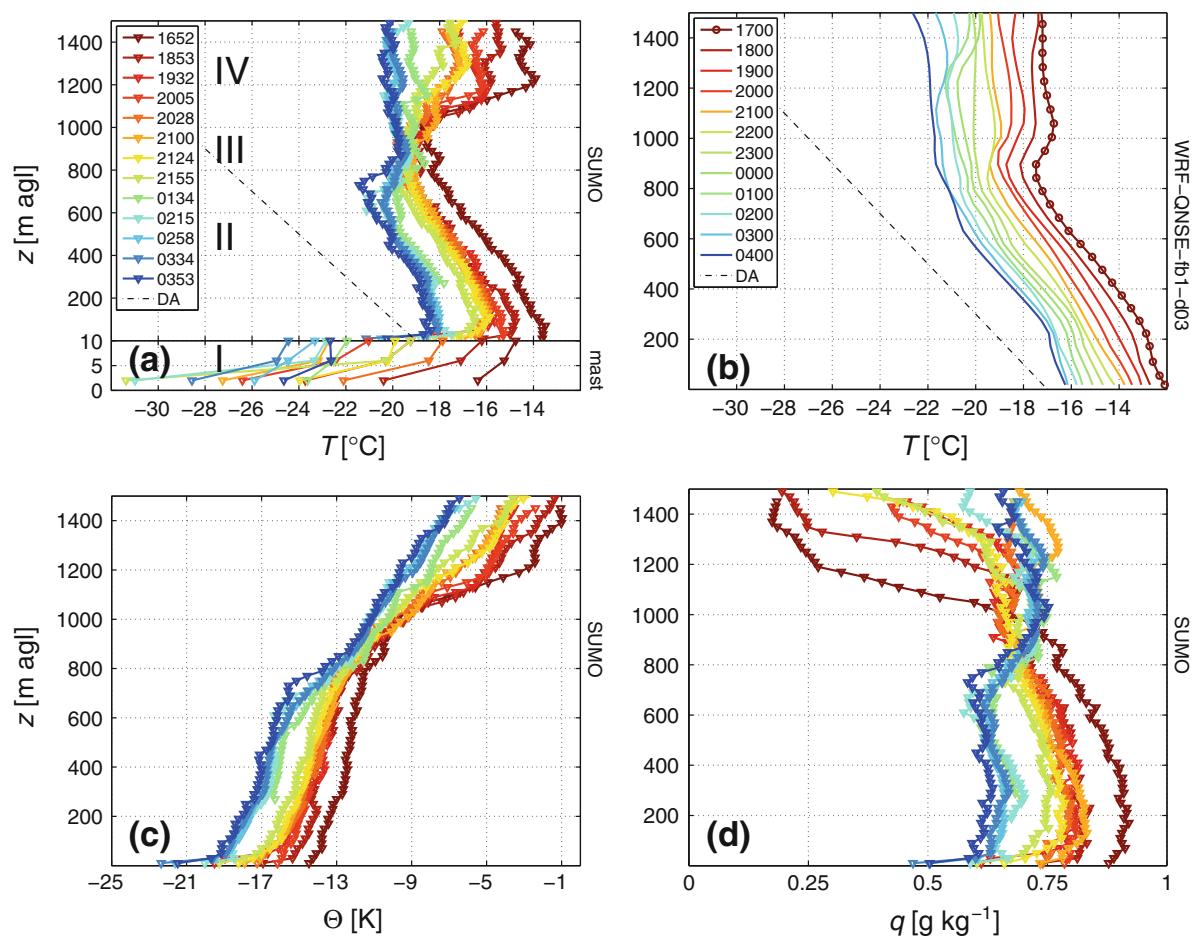

Fig. 7 SUMO profiles for a temperature, $\mathbf{c}$ potential temperature and $\mathbf{d}$ specific humidity profiles at the Auroral Station during the course of the night of 31 March until 1 April 2009. The temperature profiles in a are supplemented by temperature measurements from the 10-m mast. DA dry adiabate. The Roman numerals in a indicate distinct layers discussed in Sect. 6.2. The corresponding WRF model temperature profiles are shown in $\mathbf{b}$; red circles indicate vertical model levels

Figure 8 shows the corresponding wind-speed and wind-direction profiles. Close to the ground $(2-10 \mathrm{~m})$ the wind speed is small $\left(<4 \mathrm{~m} \mathrm{~s}^{-1}\right)$ with flow from easterly to south-easterly directions throughout the whole period. As described in Sect. 3, no reliable wind data are available from the SUMO system below $200 \mathrm{~m}$. Above, in general, northerly winds prevail up to $1500 \mathrm{~m}$ except for the layer $800-1200 \mathrm{~m}$ where a distinct veering occurs throughout the night and at 200-400 m where south-easterly winds are observed in the morning hours. In the beginning, the slight backing of the wind with height indicates cold-air advection in the lower atmosphere. The wind-speed profiles of late afternoon and evening show two maxima, one at the centre of layer II at around $400 \mathrm{~m}$, reaching $6 \mathrm{~m} \mathrm{~s}^{-1}$ and an even more pronounced maximum reaching $8 \mathrm{~m} \mathrm{~s}^{-1}$ at around $1100 \mathrm{~m}$. Around $800 \mathrm{~m}$, i.e. at the base of the strong inversion layer, a minimum wind speed of $2-4 \mathrm{~m} \mathrm{~s}^{-1}$ is observed. The first peak in the wind profiles in layer II can be associated with a weak jet in the valley's centre. In the early morning, the wind-speed profile has gradually changed, and the lowest accessible layer by SUMO at around $200 \mathrm{~m}$ shows now an indication of a low-level jet, just above the very stable surface layer. Aloft, the wind speed decreases close to zero at around $400 \mathrm{~m}$, slightly increasing around $600 \mathrm{~m}$ before reaching another minimum close to zero at $800 \mathrm{~m}$. Above that level, the wind speed increases linearly to about $6 \mathrm{~m} \mathrm{~s}^{-1}$ at $1500 \mathrm{~m}$. 

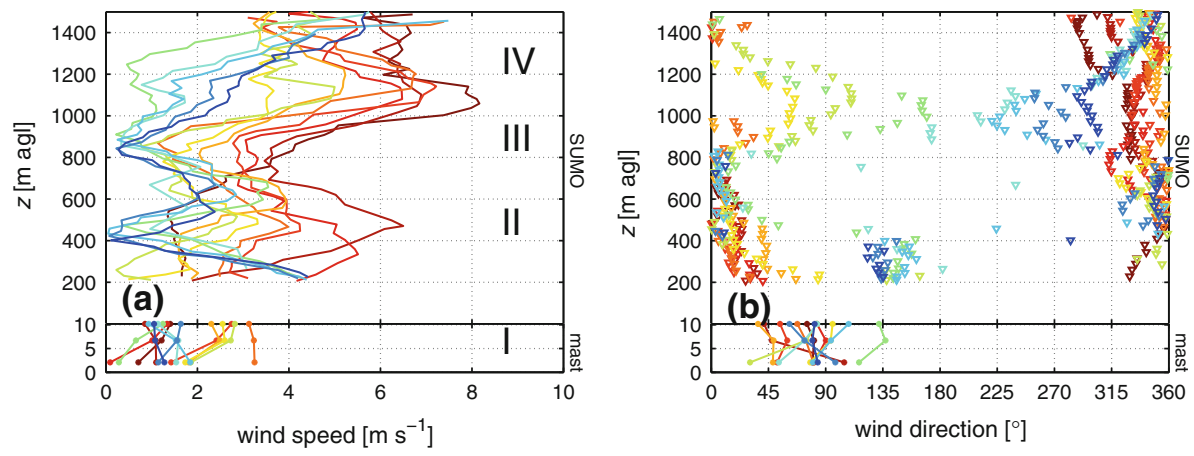

Fig. 8 SUMO wind profiles and measurements from the $10-\mathrm{m}$ mast at the Auroral Station during case 2. Colour code as in Fig. 7a

\subsection{Discussion}

The atmospheric profiles taken during the night reveal two interesting features worthwhile to be further analyzed. The first is the relatively small cooling $(<2 \mathrm{~K})$ in layer III compared to that of layers II and IV, also shown by the average layer temperatures in Fig. 10. The second is the strong and systematic variation of the wind direction during the night in the layer between $900 \mathrm{~m}$ and $1100 \mathrm{~m}$. The corresponding temperature profiles from WRF model simulations are shown in Fig. $7 \mathrm{~b}$, and also reveal the general cooling seen in the observations. The model profiles show a warm bias of $\approx 2 \mathrm{~K}$, but the amount and rate of cooling at least in the layers II (around $4 \mathrm{~K}$ ) and IV (around $5 \mathrm{~K}$ ) are well captured. However, large qualitative and quantitative differences occur in layer III. The model inversion in the late afternoon is by far weaker $\left(\approx 1 \mathrm{~K}(100 \mathrm{~m})^{-1}\right)$ and located about $100 \mathrm{~m}$ lower than the observed one. It weakens in the early morning hours. During the night the model layer III cools similar to layer IV above. The model shows no indication of the observed sharp inversion at around $700 \mathrm{~m}$ and the observed temperature decrease in layer III is far less than that predicted by the model.

An explanation for this observed reduced amount of cooling could be the existence of a trapped gravity wave in this layer (ca. 800-1000 m). Assuming that the wave is in its downward moving phase and more or less stationary during the night could explain a compression of the downward moving air damped by the stable layer in the valley (see the over time downward moving kink in the $T$ profile (Fig. 7a) and $\Theta$ profile (Fig. 7c). For a closer investigation of this hypothesis, the Scorer parameter $l^{2}$ (Scorer 1949) has been used, and which combines the effects of atmospheric stability and wind shear:

$$
l^{2}=\frac{N^{2}}{\bar{U}^{2}}-\frac{1}{\bar{U}} \frac{d^{2} \bar{U}}{d z^{2}},
$$

where the first term denotes the ratio between the Brunt-Vaisala frequency $N^{2}$ and the square of the mean wind $\bar{U}$. The second term is the curvature of the wind-speed profile describing the prevailing wind shear. The variation of $l^{2}$ with height allows for the prediction of the existence and behaviour of gravity waves in the atmosphere. In general a decrease of $l^{2}$ with height favours vertically propagating waves, while an increase of $l^{2}$ with height leads to trapping (e.g. Holton (1992)). The temperature and wind profiles from SUMO have been used to calculate the corresponding profiles of the 
Fig. 9 Profiles of the Scorer parameter: colour code as in Fig. 7a

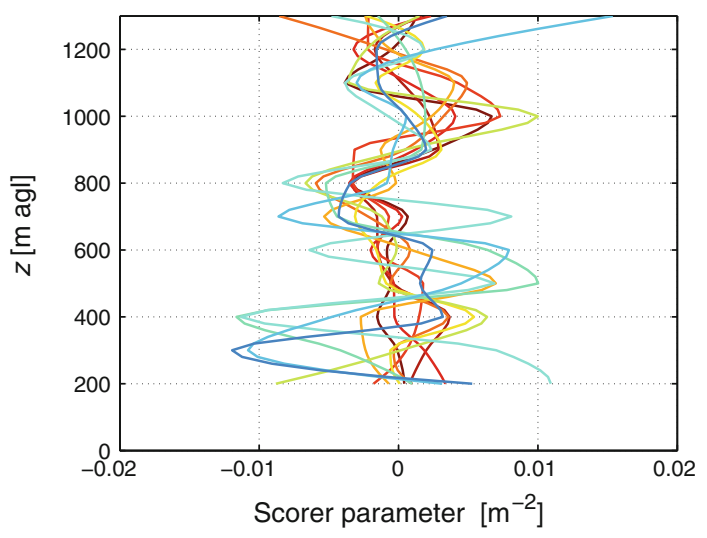

Scorer parameter (see Fig. 9). The temporal variation of $l^{2}$ towards the morning is rather high, in particular in layers II and IV. In contrast, layer III (800-1000 m) shows distinctly reduced variability and during the whole period a marked increase of $l^{2}$ with height topped by a local maximum, potentially leading to the situation of a trapped gravity wave over a long period. The corresponding warming in the 'sandwich' layer (see black circles in Fig. 10 after 2100) that is superimposed on the mesoscale cold-air advection, results in the observed reduced cooling compared to the layers above and below.

The second feature of interest is the temporal behaviour of the wind direction at that level. After 2100 the wind starts to veer from north through east (2200) to south (0130) and finally to west (0330). The situation is visualized in more detail in Fig. 11, where the temporal evolution of the average horizontal wind vectors in the layer $900-1100 \mathrm{~m}$ is shown. Layer III, roughly at the level of the surrounding mountains, seems to be unusual by separating the valley from the free atmosphere. The data indicate that the inner-valley air in the layer 0-800 $\mathrm{m}$ is decoupled from the free atmosphere above by a strong inversion, leading to a lack of friction between the layers III and IV. Averaging the measured wind components in this altitude region (see Fig. 11) shows a distinct and systematic clockwise veering of the horizontal wind vector indicating inertial flow. By theory an inertial period of $2 \Pi / f \approx 12$ $\mathrm{h}$ is expected for the measurement location at $78^{\circ} \mathrm{N}$, where $f$ represents the corresponding Coriolis parameter. The rotation of the wind vectors in Fig. 11, nearly completing a full circle during the observation period of 11 hours, is in good agreement with this theory. Hence, we argue that the warming in layer III is caused by a trapped inertial-gravity wave.

\section{Summary}

During a two-week field experiment in Arctic environment, the SUMO system operated reliably and successfully even under very low temperatures. The system proved its potential for atmospheric profiling in such conditions with a time resolution of around 30 minutes. The relatively strict interpretation of the flight permission given by the Norwegian CAA by the local staff at Longyearbyen airport, limited the acquisition of a more complete dataset, e.g. by taking subsequent profiles during the course of a full day. SUMO operations were only allowed when the airport was closed, i.e. usually during the nighttime and on the weekends. For future applications routines have to be established that would allow a more frequent profiling, desired and required for advanced observation of $\mathrm{ABL}$ evolution and transition 
Fig. 10 Quasi-time series of SUMO mean temperatures in the layers 400-600 m, 800-1000 m and $1200-1400 \mathrm{~m}$ during case 2

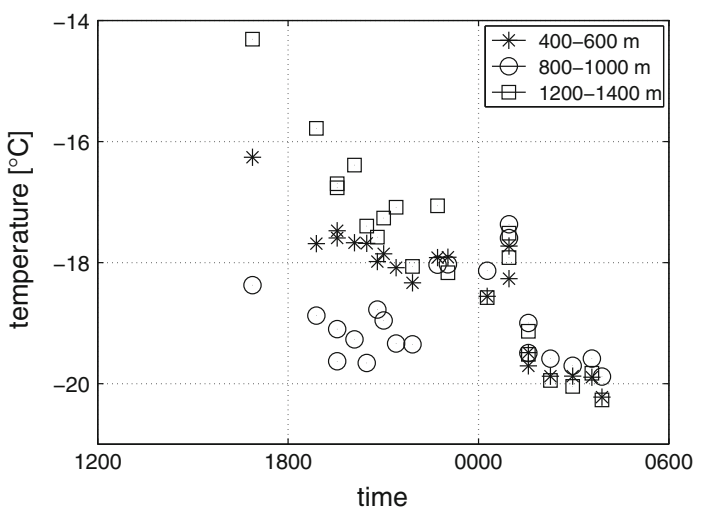

Fig. 11 Averaged horizontal wind components shown as vectors for the layer 900-1100 m. Colour code corresponds with the SUMO profiles shown in Fig. 7a

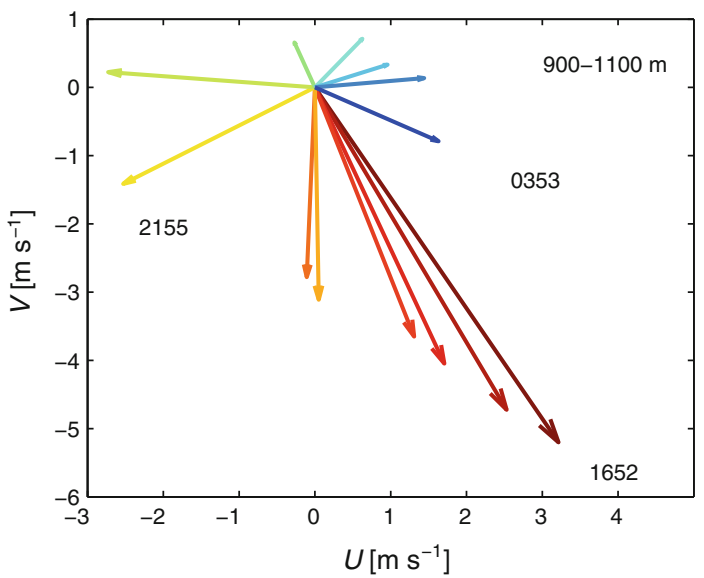

processes. Nevertheless, the gathered dataset provided an appropriate and valuable basis for a comparison with parallel tethered balloon ascents and a validation of the WRF model with respect to the sensitivity of different ABL parametrization schemes in stable atmospheric conditions. Intense measurements during the night of 31 March until 1 April 2009 provided deeper insight into the complex interaction between atmosphere and orography in the stable Arctic ABL.

By operating a tethered balloon system simultaneously with the SUMO aircraft at Longyear airport both measurement systems could be compared with each other. It can be concluded that the SUMO profiles have at least the quality of tethered balloon measurements for levels above $200 \mathrm{~m}$. SUMO outperforms the tethered balloon system in terms of flexibility, transportability and for the penetration of strong inversion layers. The tethered balloon system has its strength at lower levels, providing important information, e.g. with respect to wind information and for temperature measurements in very strong surface inversions. Therefore, it is an ideal tool to bridge the gap between surface measurements $(2-10 \mathrm{~m})$ and SUMO profiles in the altitude region of 50-200 $\mathrm{m}$.

We presented high-resolution WRF model simulations performed with different ABL schemes. The sensitivity to the choice of ABL scheme and horizontal resolution has been evaluated by using SUMO profile measurements as a reference. The QNSE scheme improves 
the temperature forecast slightly in stable conditions, however, all schemes show a warm bias close to the surface and a cold bias above the ABL.

The possibility to operate SUMO subsequently during one night in Advent Valley gave a more detailed picture of thermal and dynamical processes not resolved appropriately in the model integrations. In the surface layer such processes can be nighttime cooling due to outgoing longwave radiation and additional drainage processes leading to an extreme surface inversion above the snow-covered valley bottom. The presence of a trapped inertial-gravity wave in the atmospheric layer aloft of the valley at the level of the surrounding mountains has not been captured by the model. A higher vertical resolution in these layers and an improved representation of the topography might overcome these shortcomings in the shown NWP model integrations.

Acknowledgements The field work was financed by the Arctic Field Grant 2009 (Svalbard Science Forum RIS ID 3346). Travel expenses for the co-authors M. O. Jonassen and J. Reuder have been covered by Meltzerfondet and an IPY-Thorpex Norwegian Research Council grant number 175992/S30. Special thanks to Avinor at Longyearbyen airport for a cooperative working environment, and to meteorologikonsulent Torgeir Mørk (met.no) for kindly providing meteorological data from Longyear airport. The authors are grateful to UNIS for the accessibility of the old Auroral Station in Adventdalen. Thanks to Andøya Rocket Range for the permission to use their facilities at Longyear airport. Many thanks to Tor de Lange (GFI) for his great commitment in installing the weather mast in $\mathrm{AV}$ in extreme weather conditions. The tethered balloon data were kindly provided by Tiina Kilpeläinen and Miina Manninen. The authors wish to acknowledge the work and commitment of the pilots Martin Müller and Christian Lindenberg. We thank Thomas Spengler for the valuable discussions on boundary-layer dynamics of the case study. Supercomputing resources, on a Cray XT4 computer at Parallab at the University of Bergen, have been made available by the Norwegian Research Council. Finally, the authors are grateful to the three anonymous reviewers who distinctly improved the manuscript by constructive criticism. This is publication no. A 389 from the Bjerknes Centre for Climate Research.

Open Access This article is distributed under the terms of the Creative Commons Attribution License which permits any use, distribution, and reproduction in any medium, provided the original author(s) and the source are credited.

\section{References}

Brisset P, Drouin A, Gorraz M, Huard P, Tyler J (2006) The Paparazzi solution. MAV2006, Sandestin, Florida Chen F, Dudhia J (2001) Coupling an advanced land surface-hydrology model with the Penn State-NCAR MM5 modeling system. Part I: model implementation and sensitivity. Mon Weather Rev 129(4):569-585

Chou M, Suarez M (1999) A solar radiation parameterization for atmospheric studies. NASA Tech Memo 104606:40

Curry J, Maslanik J, Holland G, Pinto J (2004) Applications of Aerosondes in the Arctic. Bull Am Meteorol Soc 85(12): 1855-1861

De Wekker S, Whiteman C (2006) On the time scale of nocturnal boundary layer cooling in valleys and basins and over plains. J Appl Meteorol Climatol 45(6):813-820

Dethloff K, Abegg C, Rinke A, Hebestadt I, Romanov V (2001) Sensitivity of arctic climate simulations to different boundary layer parameterizations in a regional climate model. Tellus A 53(1):1-26

Galperin B, Sukoriansky S, Perov V (2007) Implementation of the Quasi-Normal Scale Elimination (QNSE) turbulence model in WRF. 8th WRF Users' Workshop, Boulder CO, June 2007

Hanssen-Bauer I, Førland E (2001) Verification and analysis of a climate simulation of temperature and pressure fields over Norway and Svalbard. Clim Res 16:225-235

Hines K, Bromwich D, Bai LS, Barlage M, Slater A (2011) Development and testing of Polar WRF. Part III. Arctic land. J Climate 24:26-48

Holton JR (1992) An introduction to dynamic meteorology, 3rd edn. Academic Press Inc., New York, 511 pp

Hong S, Kim S (2007) Stable boundary layer mixing in a vertical diffusion scheme. The Korea Meteor Soc, Fall conference, Seoul, Korea, Oct 25-26

Hong S, Noh Y, Dudhia J (2006) A new vertical diffusion package with an explicit treatment of entrainment processes. Mon Weather Rev 134(9):2318-2341 
Janjic Z (1990) The step-mountain coordinate: physical package. Mon Weather Rev 118(7):1429-1443

Janjic Z (1996) The surface layer in the NCEP Eta model. 11th Conference on Numerical Weather Prediction, Am Meteorol Soc pp 354-355

Janjic Z (2002) Nonsingular implementation of the Mellor-Yamada Level 2.5 Scheme in the NCEP meso models. NCEP Office Note No. 437:61pp

Jonassen M (2008) The Small Unmanned Meteorological Observer (SUMO)—characterization and test of a new measurement system for atmospheric boundary layer research. Master's thesis, Geophysical Institute, University of Bergen

Kilpeläinen T, Vihma T, Ólafsson H (2010) Modelling of spatial variability and topographic effects over Arctic fjords in Svalbard. Tellus A 63(2):223-237

Mahrt L (1998) Nocturnal boundary-layer regimes. Boundary-Layer Meteorol 88(2):255-278

Manninen M (2009) Structure of the atmospheric boundary layer in Isfjorden, Svalbard, in late winter 2009. Master's thesis, University Center in Svalbard

Mayer S, Sandvik A, Jonassen M, Reuder J (2010) Atmospheric profiling with the UAS SUMO: a new perspective for the evaluation of fine-scale atmospheric models. Meteorol Atmos Phys. doi:10.1007/ s00703-010-0063-2

Mayer S, Hattenberger G, Brisset P, Jonassen M, Reuder R (2012) A 'no-flow sensor' wind estimation algorithm for Unmanned Aerial Systems. Int J Micro Air Veh 4(1):15-29

Mckinnon K (1996) Convergence of the Nelder-Mead simplex method to a non-stationary point. Tech rep, SIAM J Optim

Mlawer E, Taubman S, Brown P, Iacono M, Clough S (1997) Radiative transfer for inhomogeneous atmosphere: RRTM, a validated correlated-k model for the longwave. J Geophys Res 102(D14):16663-16682

Petersson C (2007) An analysis of the local weather around Longyearbyen and an instrumental comparison. Master's thesis, University Center in Svalbard

Reuder J, Brisset P, Jonassen M, Müller M, Mayer S (2009) The Small Unmanned Meteorological Observer SUMO: a new tool for atmospheric boundary layer research. Meteorol Z 18(2):141-147

Reuder J, Ablinger M, Ágústsson H, Brisset P, Brynjólfsson S, Garhammer M, Johannesson T, Jonassen M, Kühnel R, Lämmlein S, de Lange T, Lindenberg C, Malardel S, Mayer S, Müller M, Ólafsson H, Rögnvaldsson O, Schäper W, Spengler T, Zängl G, Egger J (2011) FLOHOF 2007: An overview of the mesoscale meteorological field campaign at Hofsjökull, Central Iceland. Meteorol Atmos Phys. doi:10. 1007/s00703-010-0118-4

Sandvik A, Furevik B (2002) Case study of a coastal jet at Spitsbergen-comparison of SAR and model estimated wind. Mon Weather Rev 130:1040-1051

Schicker I, Seibert P (2009) Simulation of the meteorological conditions during a winter smog episode in the Inn Valley. Meteorol Atmos Phys 103(1):211-222

Scorer R (1949) Theory of waves in the lee of mountains. Q J Roy Meteorol Soc 75(323):41-56

Seibert P, Beyrich F, Gryning SE, Joffre S, Rasmussen A, Tercier P (2002) Review and intercomparison of operational methods for the determination of the mixing height. Dev Environ Sci 1:569-613

Skamarock W, Klemp J, Dudhia J, Gill D, Barker D, Duda M, Huang XY, Wang W (2008) A Description of the Advanced Research WRF Version 3. NCAR/TN:475+STR

Skeie P, Grønås S (2000) Strongly stratified easterly flows across Spitsbergen. Tellus A 52(5):473-486

Stull RB (1988) An introduction to boundary layer meteorology. Kluwer Academic Publishers, Boston, $666 \mathrm{pp}$

Sukoriansky S, Galperin B (2008) Anisotropic turbulence and internal waves in stably stratified flows (QNSE theory). Physica Scripta 132:14-36

Tjernström M, Zagar M, Svensson G (2004) Model simulations of the Arctic atmospheric boundary layer from the SHEBA year. AMBIO J Human Environ 33(4):221-227

Tjernström M, Zagar M, Svensson G, Cassano J, Pfeifer S, Rinke A, Wyser K, Dethlo K, Jones C, Semmler T, Shaw M (2005) Modelling the Arctic boundary layer: an evaluation of six ARCMIP regional-scale models using data from the SHEBA project. Boundary-Layer Meteorol 117:337-381

Troen I, Mahrt L (1986) A simple model of the atmospheric boundary layer; sensitivity to surface evaporation. Boundary-Layer Meteorol 37:129-148

van den Kroonenberg A, Martin T, Buschmann M, Bange J, Vörsmann P (2008) Measuring the wind vector using the autonomous Mini Aerial Vehicle $\mathrm{M}^{2}$ AV. J Atmos Ocean Technol 25:1969-1982

Zilitinkevich S, Baklanov A (2002) Calculation of the height of the stable boundary layer in practical applications. Boundary-Layer Meteorol 105(3):389-409 